\title{
The relationship between early pregnancy dietary intakes and subsequent birthweight and neonatal adiposity
}

\author{
R.A.K. Kennedy \\ University College Dublin, rachel_kennedy@live.ie \\ Laura Mullaney \\ Technological University Dublin, laura.mullaney@dit.ie
}

A.C. O'Higgins

University College Dublin

See next page for additional authors

Follow this and additional works at: https://arrow.tudublin.ie/scschbioart

Part of the Food Science Commons, and the Medicine and Health Sciences Commons

\section{Recommended Citation}

Kennedy RAK, Mullaney L, O'Higgins AC, Doolan A, McCartney DM, Turner MJ. The relationship between early pregnancy dietary intakes and subsequent birthweight and neonatal adiposity. J Public Health (Oxf). 2018 Dec 1;40(4):747-755. doi: 10.1093/pubmed/fdx131. PMID: 30590769.

This Article is brought to you for free and open access by the School of Biological Sciences at ARROW@TU Dublin. It has been accepted for inclusion in Articles by an authorized administrator of ARROW@TU Dublin. For more information, please contact arrow.admin@tudublin.ie, aisling.coyne@tudublin.ie,gerard.connolly@tudublin.ie.

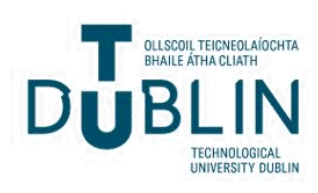




\section{Authors}

R.A.K. Kennedy, Laura Mullaney, A.C. O'Higgins, A. Doolan, Daniel McCartney, and M.J. Turner 


\title{
The relationship between early pregnancy dietary intakes and subsequent birthweight and neonatal adiposity
}

\author{
R. A. K. Kennedy ${ }^{1,2}$, L. Mullaney ${ }^{1,2}$, A. C. O’Higgins ${ }^{1}$, A. Doolan ${ }^{1}$, D. M. McCartney ${ }^{2}$, \\ M. J. Turner ${ }^{1}$ \\ ${ }^{1}$ UCD Centre for Human Reproduction, Coombe Women and Infants University Hospital, Cork Street, Dublin 8, Ireland \\ ${ }^{2}$ School of Biological Sciences, Dublin Institute of Technology, Kevin Street, Dublin 8, Ireland \\ Address correspondence to Rachel Kennedy, E-mail: rachel_kennedy@live.ie
}

\section{ABSTRACT}

Background Maternal nutrition intakes may influence neonatal birthweight and adiposity; however, inconsistencies within the literature exist. The relationships between maternal dietary intakes in early pregnancy and both birthweight and neonatal adiposity requires elucidation. This study examined the relationship between early pregnancy dietary intakes and subsequent birthweight and neonatal adiposity.

Methods Women were recruited at their convenience after sonographic confirmation of a singleton pregnancy. Women completed a Willet food frequency questionnaire evaluating habitual food and nutrient intakes at their first antenatal visit. Neonatal body composition was measured using air-displacement plethysmography.

Results Of the 385 mother-neonate dyads, mean maternal age was $30.8 \pm 5.3$ years, mean Body Mass Index (BMI) was $24.5 \pm 4.8 \mathrm{~kg} / \mathrm{m}^{2}$ and $41.8 \%(n=161)$ were nulliparous. There were no relationships between maternal food intakes and birthweight $(P>0.05)(n=385)$. On multivariable analysis there was a positive relationship between polyunsaturated fat and neonatal fat mass index $(\mathrm{FMI})(\mathrm{beta}=0.015,95 \% \mathrm{Cl}=$ $0.002-0.028, P=0.04)(n=80)$.

Conclusion Dietary intakes of polyunsaturated fat in early pregnancy are positively associated with neonatal FMI at birth on multivariable analysis. Further longitudinal studies need to explore this association and the long-term implications for the neonate.

Keywords food and nutrition, neonates, public health

\section{Introduction}

Foetal growth is complex, with the foetus requiring the appropriate intrauterine environment to support its optimal growth and development. ${ }^{1,2}$ There are many parameters at play in utero which may influence foetal development, such as the woman's metabolic status, her lifestyle behaviours and her nutritional intake both periconceptionally and over the course of her pregnancy. ${ }^{3-5}$

Neonatal anthropometric outcomes are linked to the metabolic status and health outcomes of the offspring in later life. ${ }^{6,7}$ For instance, low birthweight has been linked to increased likelihood of cardiovascular disease, Type 2 Diabetes Mellitus (T2DM) and metabolic syndrome. ${ }^{8,9}$ Similarly, macrosomic neonates are at increased risk of adult obesity and T2DM. ${ }^{10,11}$ Less well studied is neonatal adiposity composition and its associations with long-term health.
Emerging evidence suggests, however, that neonates with higher neonatal adiposity may be at increased risk of health complications such as insulin resistance, which may influence metabolic health in adulthood. ${ }^{12,13}$

Nutrient availability in pregnancy is an important determinant of foetal growth and, therefore, impacts birthweight and neonatal body composition. ${ }^{14,15}$ Inadequate intakes of key nutrients at critical periods of gestation can have lasting deleterious effects on the developing foetus. ${ }^{5}$ For example, low-maternal iron status has been linked with low
R. A. K. Kennedy, Research Dietitan
L. Mullaney, Research Dietitian
A. C. O'Higgins, Lecturer
A. Doolan, Consultant Neonatologist
D. M. McCartney, Lecturer, Human Nutrition and Dietetics
M. J. Turner, Professor 
birthweight $^{16}$ and, low vitamin $\mathrm{D}$ status has been linked with low birthweight and poor skeletal development. ${ }^{17-20}$ Additionally, maternal dietary composition may influence neonatal adiposity. Research has found that maternal dietary intakes during pregnancy are associated with neonatal adiposity. However, further research is needed to determine optimal macro- and micro-nutrients distributions in pregnancy to promote favourable neonatal adiposity, which may reduce the likelihood of adverse metabolic profiles later in life. $^{21}$

It is evident that the most advantageous nutritional intakes in pregnancy, as well as the most favourable birthweight and neonatal body composition at birth, still remain to be fully elucidated. ${ }^{22,23}$ There is a paucity of research examining neonatal adiposity using direct measurement such as air-displacement plethysmography. Of the existing literature, the results are inconsistent and many rely on surrogate measurements for adiposity measurements, such as skinfold thickness or ponderal index. ${ }^{24}$ Skinfold thickness measurements introduce the risk of inter-observer variation and may compromise the accuracy of the data collected. Ponderal index, may only reflect total adiposity and does not offer insights into fat distribution. Furthermore, evidence has shown, this measurement may be a poor predictor of total neonatal body adiposity. ${ }^{25}$

It has been challenging to draw conclusions from existing literature examining the relationship between maternal nutrition and foetal growth parameters, given the heterogeneity in terms of methodology, study populations and the nutrients under investigation. ${ }^{24,26}$ Furthermore, there is a need for research to examine the impact of maternal maco- and micro-nutrient intakes on both neonatal birthweight and adiposity, using a direct measurement, in the same study cohort.

\section{Aim}

This study examined the relationship between early pregnancy food and nutrient intakes and subsequent birthweight and neonatal adiposity.

\section{Methods}

\section{Maternal data collection}

This study was a secondary analysis of a longitudinal study investigating maternal weight trajectories in pregnancy and the post-partum period. ${ }^{27}$ Women were recruited at their first antenatal visit before 18 weeks gestation following ultrasound confirmation of an ongoing singleton pregnancy. Al women were recruited at their convenience between
February and August 2013. The Coombe Women and Infants University Hospital (CWIUH) is one of the largest maternity hospitals in the European Union (EU) and cares for women from all socioeconomic groups and from across the urban-rural divide. Women's clinical and sociodemographic details were computerized routinely at the first antenatal visit and updated immediately after delivery. ${ }^{28}$

Exclusion criteria included multiple pregnancies, age $<18$ years, gestation $>18$ weeks at booking, and delivery at another centre. Written informed consent was obtained from all study participants.

Height was measured to the nearest centimetre using a Seca wall-mounted digital metre stick with the woman standing in her bare feet looking straight forward with her head held in the Frankfort position. Weight was measured digitally to the nearest $0.1 \mathrm{~kg}$ (Tanita MC 180, Tokyo, Japan) and Body Mass Index (BMI) calculated.

\section{Food frequency questionnaire}

Women's habitual food and nutrient intakes were collected using a self-administered, semi-quantitative Willet food frequency questionnaire (WFFQ), which women completed unsupervised at their first antenatal visit. This WFFQ was adapted from the European Prospective Investigation into Cancer and Nutrition (EPIC) study and validated for use in a population of Irish adults. ${ }^{29-31}$ The WFFQ has also more recently been validated in an Irish obstetric population. ${ }^{32}$

The adapted WFFQ contains 170 food and beverage items. Frequency of consumption of a standard portion of each food or beverage item consumed is divided into nine categories which range from 'never or less than once per month' to 'six or more times per day'. 33 This tool collects food intake data reflective of the previous year from the time of completion, and food and nutrient intake estimations derived from these data are thus reflective of early pregnancy and the periconceptional period. The WFFQ data were entered into WISP version 4.0 (Tinuviel Software, Llanfechell, Anglesey, UK) to convert women's reported dietary intakes into nutrient intakes. ${ }^{33}$ The food composition tables used in WISP are derived from McCance and Widdowson's Food Composition tables fifth and sixth editions, and all supplemental volumes. ${ }^{33,34}$

\section{Lifestyle information}

Self-estimated habitual physical activity levels (PALs) were collected using a self-administered, unsupervised questionnaire. Individual PALs were estimated for each woman using six categories: 1.45 metabolic equivalents (METs), seated work with no option of moving around and no strenuous leisure time activity; 1.60 METs, seated work with discretion 
and requirement to move around but no strenuous leisure time; 1.75 METs, active commute/daily walk with seated work and some requirement to move around, 1.90 METs, standing work (extended periods of standing or walking daily) and moderately active leisure time; 2.05 METs, standing work (extended periods of standing or walking daily) and active leisure time, and finally, 2.20 METs, strenuous work or highly active leisure time (e.g. competitive athletes in daily training). ${ }^{35}$

\section{Assessment of energy under-reporting and over-reporting}

Women's basal metabolic rate (BMR) was calculated using standard equations based on gender, weight and age. ${ }^{36}$ Energy Intake (EI) was calculated using WFFQ food intake data and WISP v 4.0 software (Tinuviel Software Ltd.). Lowest plausible thresholds for PAL were calculated using women's self-reported PAL. ${ }^{37}$ Women whose ratio of EI to their calculated BMR (EI/BMR) fell below of the calculated plausible threshold for their physical activity category were classified as dietary under-reporters. ${ }^{33,37,38}$ Women whose EI ratio to calculated BMR was $>2.5$ were categorized as dietary over-reporters. ${ }^{39}$ All dietary mis-reporters were removed from the dataset before inferential statistical analyses were undertaken.

\section{Neonatal data collection}

Infant weight and length were measured. Circumference measurements (occipital-frontal, abdominal, mid-upper arm and thigh) were taken in addition to body composition measurements (fat mass, percentage body fat, fat free mass and percentage fat free mass). All measurements were taken within three days of birth. Body composition parameters were assessed by air-displacement plethysmography (ADP) using a PEA POD ${ }^{\circledR}$ analyser (PEA POD, COSMED, Concord, CA, USA). ${ }^{40}$

The PEA POD ${ }^{\circledR}$ analyser determines percent body fat and fat free mass in infants by application of the theory of whole body densitometry. ${ }^{41}$ Infant volume, calculated using gas laws and direct measurement of body mass, are used to calculate density. The infants' body density is then used to calculate percentage fat and fat free mass. Percentage body fat is calculated by use of age and gender specific fat free mass density values. ${ }^{41,42}$ The PEA POD ${ }^{\circledR}$ analyser is used for measurements of body composition in infants weighing between 1.0 and $8.0 \mathrm{~kg}^{42}$

For the PEA POD ${ }^{\circledR}$ measurement, the neonate had all clothing removed. Any un-removable items such as the hospital security tag, name tags and umbilical clamp were used to tare the scales and volume chamber. ${ }^{40}$ The neonate's hair was smoothed down with water to limit its isothermal activity. Further maternal and neonatal data were derived from hospital records including maternal diabetes status, maternal parity, infant gestational age at birth and infant gender. The study was approved by the Coombe Women and Infants University Hospital Research Ethics Committee (Study number 7-2012).

\section{Statistical analysis}

Data were analysed using IBM SPSS statistics version 22.0 (IBM Corporation, Armonk, New York). Continuous variables were assessed for normality by determination of the kurtosis and skewness of the distribution, visual inspection of their histograms and assessment of their KolmogorovSmirnov statistics. Descriptive statistics were used to describe the general characteristics of the study participants.

Infant neonatal fat mass (FM) was adjusted for neonatal length and, therefore, expressed as fat mass index (FMI; FM $\left.(\mathrm{kg}) /(\text { length }(\mathrm{m}))^{2}\right)$. This is considered to be the best proxy for neonatal body composition and adiposity. ${ }^{14,43,44}$ Simple linear regression was used to determine the associations between maternal food and nutrient intakes and neonatal birthweight and FMI. A separate linear model was run for each nutrient of interest. The variables significantly associated with neonatal FMI on univariate analysis were included in a multivariable linear regression model(s). Model 1, controlled for maternal BMI, Model 2 controlled for maternal BMI, neonatal gender and gestational age at birth, and Model 3 included polyunsaturated fat and controlled for maternal BMI, infant gender and gestational age at birth. A $P$-value of $<0.05$ was considered statistically significant.

\section{Results}

A total of 524 women with completed WFFQ data were recruited to the study. Of these, 402 women were classified as plausible dietary reporters, and 122 women were classified as dietary under-reporters. There were no dietary overreporters in the sample. Of the plausible reporters, there were 385 women who also had neonatal measurements taken, with PEA POD ${ }^{\circledR}$ analysis performed on 80 neonates within 3 days of birth.

Table 1 outlines the characteristics of the study population included in analysis $(n=385)$. Of the women included in the analysis, $12.7 \%(n=49 / 385)$ reported their smoking status as 'current smoker' at their first antenatal visit and over half of women $(57.4 \%, n=221 / 385)$, reported habitually 
Table 1 Study population characteristics $(n=385)$

\begin{tabular}{|c|c|c|c|c|c|c|c|}
\hline & \multicolumn{2}{|c|}{ Total population $(\mathrm{n}=385)$} & \multicolumn{2}{|c|}{$\begin{array}{l}\text { Those without neonatal } \\
\text { adiposity measurements } \\
(\mathrm{n}=305)\end{array}$} & \multicolumn{2}{|c|}{$\begin{array}{l}\text { Those with neonatal adiposity } \\
\text { measurements }(\mathrm{n}=80)\end{array}$} & \multirow[t]{2}{*}{$P$} \\
\hline & $\mathrm{n}$, mean, median & $\%, S D, I Q R$ & $\mathrm{n}$, mean, median & $\%, S D, I Q R$ & $\mathrm{n}$, mean, median & $\%, S D, I Q R$ & \\
\hline \multicolumn{8}{|l|}{ Maternal characteristics } \\
\hline Maternal age [years; mean, SD] & 30.8 & 5.3 & 30.9 & 5.3 & 30.1 & 4.8 & 0.21 \\
\hline Nulliparous [n, \%] & 161.0 & 41.8 & 122.0 & 40.0 & 39.0 & 48.8 & 0.16 \\
\hline Maternal BMI [kg/m²; mean, SD] & 24.5 & 4.8 & 24.7 & 4.9 & 24.4 & 4.4 & 0.64 \\
\hline \multicolumn{8}{|l|}{ Maternal BMI category [n, \%] } \\
\hline Underweight & 4.0 & 3.6 & 12.0 & 3.9 & 2.0 & 2.5 & - \\
\hline Ideal weight & 214.0 & 55.6 & 168.0 & 55.1 & 46.0 & 57.5 & 0.70 \\
\hline Overweight & 115.0 & 29.9 & 92.0 & 30.2 & 23.0 & 28.7 & 0.80 \\
\hline Obese & 42.0 & 10.9 & 33.0 & 10.9 & 9.0 & 11.2 & 0.91 \\
\hline Smokers $[n, \%]$ & 49.0 & 12.7 & 43.0 & 14.1 & 6.0 & 7.5 & 0.19 \\
\hline Drink alcohol habitually [n, \%] & 221.0 & 57.4 & 175.0 & 57.4 & 46.0 & 57.5 & 0.98 \\
\hline GDM & 10.0 & 2.6 & 7.0 & 2.3 & 3.0 & 3.8 & - \\
\hline Pre-existing diabetes & 6.0 & 1.6 & 5.0 & 1.6 & 1.0 & 1.3 & - \\
\hline \multicolumn{8}{|l|}{ Neonatal characteristics } \\
\hline Males & 201.0 & 52.2 & 157.0 & 51.5 & 44.0 & 55.0 & 0.57 \\
\hline Females & 184.0 & 47.8 & 148.0 & 48.5 & 36.0 & 45.0 & 0.57 \\
\hline Gestational age at birth [median, IQR] & 40.0 & 1.9 & 40.0 & 2.0 & 40.2 & 1.7 & 0.26 \\
\hline
\end{tabular}

SD, standard deviation; IQR, inter quartile range; kg, kilogram; m, metre; -, insufficient sample to perform analysis; BMI, body mass index; GDM, gestational diabetes mellitus.

Table 2 Neonatal anthropometric characteristics $(n=385)$

\begin{tabular}{|c|c|c|c|c|c|c|c|c|c|}
\hline \multirow[t]{2}{*}{ Neonatal characteristics } & \multicolumn{3}{|c|}{ Total cohort } & \multicolumn{3}{|c|}{ Males } & \multicolumn{3}{|c|}{ Females } \\
\hline & $n$ & mean & $S D$ & $n$ & mean & $S D$ & $\mathrm{n}$ & mean & $S D$ \\
\hline Birthweight (kg) & 385 & 3.50 & 0.58 & 201 & 3.48 & 0.60 & 184 & 3.42 & 0.57 \\
\hline Fat mass $(\mathrm{kg})$ & 80 & 0.32 & 0.16 & 44 & 0.31 & 0.17 & 36 & 0.34 & 0.15 \\
\hline Percentage fat mass (\%) & 80 & 9.44 & 3.90 & 44 & 8.76 & 4.06 & 36 & 10.28 & 3.67 \\
\hline FMI $\left[(\mathrm{kg}) /(\text { length }(\mathrm{m}))^{2}\right]$ & 80 & 1.27 & 0.60 & 44 & 1.20 & 0.63 & 36 & 1.35 & 0.50 \\
\hline Infant length at birth (cm) & 81 & 50.09 & 2.00 & 45 & 50.38 & 1.97 & 36 & 49.73 & 2.00 \\
\hline Occipital-frontal circumference $(\mathrm{cm})$ & 81 & 34.85 & 1.29 & 45 & 35.17 & 1.23 & 36 & 34.45 & 1.27 \\
\hline Mid-upper arm circumference (cm) & 80 & 10.70 & 1.06 & 44 & 10.72 & 0.94 & 36 & 10.76 & 1.20 \\
\hline Mid-thigh circumference (cm) & 80 & 15.97 & 1.32 & 44 & 15.26 & 1.40 & 36 & 14.83 & 1.19 \\
\hline Abdominal circumference $(\mathrm{cm})$ & 80 & 33.99 & 2.20 & 44 & 33.20 & 2.09 & 36 & 32.34 & 2.32 \\
\hline
\end{tabular}

SD, standard deviation; cm, centimetres; kg, kilograms; m, metre; FM, fat mass.

consuming alcohol. Table 2 describes the characteristics of the neonatal study population.

Table 3 outlines the associations between maternal macroand micro-nutrients intakes in early pregnancy and birthweight, and neonatal FMI using simple linear regression. On univariate analysis, total fat (beta $=0.004,95 \% \mathrm{CI}=$ $0.001-0.007, P=0.02$ ), monounsaturated fat (beta $=0.010$,
95\% CI $=0.001-0.02, P=0.04)$, polyunsaturated fat (beta $=0.021,95 \% \mathrm{CI}=0.007-0.04, P=0.004)$ and vita$\min \mathrm{E}$ (beta $=0.020,95 \% \mathrm{CI}=0.00-0.045, P=0.048$ ) were each positively associated with neonatal FMI. Removal of potential confounding variables gestational diabetes mellitus (GDM) and pre-existing diabetes did not result in any change in the findings outlined in Table 3. 
Table 3 Simple linear regression between maternal macro-nutrient and micro-nutrients intakes and neonatal outcomes

\begin{tabular}{|c|c|c|c|c|c|c|c|c|c|c|c|c|}
\hline & \multicolumn{6}{|c|}{ Birthweight $(n=385)$} & \multicolumn{6}{|c|}{$F M I(n=80)$} \\
\hline & \multicolumn{2}{|c|}{ Unstandardized } & \multirow{2}{*}{$\begin{array}{l}\text { Standardized } \\
\text { Beta }\end{array}$} & \multirow[b]{2}{*}{$\mathrm{t}$} & \multirow[b]{2}{*}{$95 \% \mathrm{Cl}$} & \multirow[b]{2}{*}{$P$} & \multicolumn{2}{|c|}{ Unstandardized } & \multirow{2}{*}{$\begin{array}{l}\text { Standardized } \\
\text { Beta }\end{array}$} & \multirow[b]{2}{*}{$\mathrm{t}$} & \multirow[b]{2}{*}{$95 \% \mathrm{Cl}$} & \multirow[b]{2}{*}{$\mathrm{P}$} \\
\hline & B & $S E$ & & & & & B & $S E$ & & & & \\
\hline \multicolumn{13}{|l|}{ Macro-nutrient } \\
\hline Carbohydrate (g) & -0.24 & 0.23 & -0.052 & -1.02 & $-0.7-0.2$ & 0.31 & 0.000 & 0.000 & 0.099 & 0.88 & $0.000-0.001$ & 0.16 \\
\hline Starch (g) & -0.45 & 0.34 & -0.068 & -1.3 & $-1.1-0.3$ & 0.18 & 0.000 & 0.000 & 0.093 & 0.82 & $-0.001-0.001$ & 0.38 \\
\hline Sugars (g) & -0.10 & 0.43 & -0.012 & -0.23 & $-1.0-0.8$ & 0.82 & 0.001 & 0.001 & 0.059 & 0.52 & $-0.002-0.003$ & 0.60 \\
\hline Fibre $(g)$ & -0.42 & 1.42 & -0.030 & -0.40 & $-3.2-2.4$ & 0.78 & 0.002 & 0.002 & 0.103 & 0.92 & $-0.002-0.006$ & 0.36 \\
\hline NMES (g) & -0.39 & 0.81 & -0.025 & -0.48 & $-2.0-1.2$ & 0.63 & 0.002 & 0.002 & 0.077 & 0.68 & $-0.003-0.006$ & 0.50 \\
\hline Protein (g) & 0.10 & 0.59 & 0.008 & 0.17 & $-1.1-1.3$ & 0.87 & 0.002 & 0.002 & 0.159 & 1.52 & $-0.001-0.005$ & 0.16 \\
\hline Fat (total) $(\mathrm{g})$ & -0.20 & 0.50 & -0.020 & -0.40 & $-1.2-0.8$ & 0.69 & 0.004 & 0.002 & 0.252 & 2.30 & $0.001-0.007$ & 0.02 \\
\hline Monounsaturated fat (g) & 0.04 & 0.91 & -0.052 & -0.10 & $-4.3-2.0$ & 0.97 & 0.010 & 0.005 & 0.236 & 2.14 & $0.001-0.02$ & 0.04 \\
\hline Polyunsaturated fat (g) & -3.22 & 3.14 & -0.040 & -0.72 & $-9.3-2.9$ & 0.48 & 0.021 & 0.007 & 0.318 & 2.96 & $0.007-0.04$ & 0.004 \\
\hline Saturated fat (g) & 0.37 & 0.91 & 0.002 & 0.04 & $-1.8-1.8$ & 0.97 & 0.008 & 0.005 & 0.179 & 1.61 & $-0.002-0.019$ & 0.11 \\
\hline \multicolumn{13}{|l|}{ Micro-nutrient } \\
\hline Calcium & 0.04 & 0.04 & 0.040 & 0.85 & $-0.05-0.1$ & 0.40 & 0.000 & 0.00 & 0.01 & 0.12 & $0.00-0.00$ & 0.91 \\
\hline Magnesium & 0.06 & 0.05 & 0.060 & 1.17 & $-0.04-0.16$ & 0.24 & 0.000 & 0.00 & 0.08 & 0.67 & $0.00-0.00$ & 0.50 \\
\hline Iron & 2.10 & 2.88 & 0.040 & 0.72 & $-3.6-7.7$ & 0.48 & 0.010 & 0.01 & 0.14 & 1.21 & $-0.005-0.021$ & 0.23 \\
\hline Zinc & -0.98 & 0.51 & -0.010 & -0.19 & $-11.0-9.0$ & 0.85 & 0.010 & 0.01 & 0.16 & 1.46 & $-0.005-0.031$ & 0.15 \\
\hline lodine & 0.06 & 0.18 & 0.020 & 0.32 & $-0.3-0.4$ & 0.72 & 0.001 & 0.001 & 0.65 & 0.58 & $-0.002-0.003$ & 0.57 \\
\hline Retinol & 0.02 & 0.03 & 0.030 & 0.61 & $-0.04-0.07$ & 0.54 & 0.000 & 0.00 & 0.11 & 0.96 & $0.00-0.00$ & 0.34 \\
\hline Carotene & -0.00 & 0.01 & -0.030 & -0.63 & $-0.01-0.01$ & 0.53 & 0.000 & 0.00 & 0.04 & 0.33 & $0.00-0.00$ & 0.74 \\
\hline Vitamin D & 1.00 & 11.20 & 0.010 & 0.09 & $-21.0-22.0$ & 0.93 & -0.002 & 0.02 & -0.01 & -0.1 & $-0.041-0.037$ & 0.93 \\
\hline Vitamin E & -2.60 & 4.90 & -0.027 & -0.52 & $-12.2-7.0$ & 0.60 & 0.020 & 0.01 & 0.22 & 2.01 & $0.00-0.045$ & 0.048 \\
\hline Thiamin & -36.08 & 28.00 & -0.070 & -1.29 & $-91.0-18.9$ & 0.20 & 0.040 & 0.06 & 0.08 & 0.67 & $-0.081-0.163$ & 0.50 \\
\hline Riboflavin & 18.70 & 29.70 & 0.030 & 0.63 & $-39.7-77.1$ & 0.53 & 0.060 & 0.08 & 0.07 & 0.69 & $-0.109-0.224$ & 0.50 \\
\hline Niacin & 0.51 & 2.70 & -0.060 & -1.25 & $-8.5-1.9$ & 0.85 & 0.010 & 0.01 & 0.15 & 1.33 & $-0.004-0.017$ & 0.21 \\
\hline Vitamin B6 & -21.90 & 24.60 & -0.050 & -0.89 & $-70.3-26.5$ & 0.37 & 0.100 & 0.05 & 0.21 & 1.88 & $-0.006-0.210$ & 0.06 \\
\hline Vitamin B12 & 1.93 & 8.50 & 0.010 & 0.23 & $-14.8-18.8$ & 0.82 & 0.010 & 0.01 & 0.10 & 0.90 & $-0.015-0.040$ & 0.37 \\
\hline Folate & 0.25 & 0.18 & 0.010 & 0.14 & $-0.33-0.38$ & 0.89 & 0.000 & 0.00 & 0.18 & 1.62 & $0.000-0.001$ & 0.11 \\
\hline
\end{tabular}

NMES, non-milk extrinsic sugars; g, grams; Cl, confidence interval. 
Table 4 Multivariable linear regression of maternal nutrient intakes and neonatal FMI $(n=80)$

\begin{tabular}{|c|c|c|c|c|c|c|}
\hline & \multicolumn{6}{|l|}{ FMI } \\
\hline & \multicolumn{2}{|c|}{$\begin{array}{l}\text { Unstandardized } \\
\text { coefficients }\end{array}$} & \multirow{2}{*}{$\begin{array}{l}\text { Standardized } \\
\text { coefficients } \\
\text { Beta }\end{array}$} & \multirow[b]{2}{*}{$\mathrm{t}$} & \multirow[b]{2}{*}{$95 \% \mathrm{Cl}$} & \multirow[b]{2}{*}{$P$} \\
\hline & B & $S E$ & & & & \\
\hline \multicolumn{7}{|l|}{ Model 1} \\
\hline \multicolumn{7}{|l|}{ Adj $R^{2}=0.265$} \\
\hline Monounsaturated fat (g) & -0.009 & 0.008 & -0.199 & -1.033 & $-0.025-0.008$ & 0.31 \\
\hline Polyunsaturated fat (g) & 0.036 & 0.017 & 0.545 & 2.131 & $0.002-0.076$ & 0.04 \\
\hline Vitamin E (mg) & -0.019 & 0.019 & -0.186 & -1.007 & $-0.025-0.008$ & 0.32 \\
\hline Maternal BMI $\left(\mathrm{kg} / \mathrm{m}^{2}\right)$ & 0.059 & 0.013 & 0.443 & 4.465 & $0.033-0.086$ & $<0.001$ \\
\hline \multicolumn{7}{|l|}{ Model 2} \\
\hline \multicolumn{7}{|l|}{$\operatorname{Adj} R^{2}=0.258$} \\
\hline Monounsaturated fat (g) & -0.008 & 0.008 & -0.196 & -1.013 & $-0.025-0.008$ & 0.31 \\
\hline Polyunsaturated fat (g) & 0.035 & 0.017 & 0.521 & 2.019 & $0.000-0.069$ & 0.047 \\
\hline Vitamin E (mg) & -0.015 & 0.019 & -0.150 & -0.797 & $-0.053-0.023$ & 0.43 \\
\hline Maternal BMI $\left(\mathrm{kg} / \mathrm{m}^{2}\right)$ & 0.059 & 0.014 & 0.444 & 4.280 & $0.032-0.087$ & $<0.001$ \\
\hline Infant gender & 0.136 & 0.120 & 0.115 & 1.132 & $-0.103-0.374$ & 0.26 \\
\hline Gestational age at birth & 0.008 & 0.040 & 0.021 & 0.202 & $-0.103-0.374$ & 0.84 \\
\hline \multicolumn{7}{|l|}{ Model 3} \\
\hline \multicolumn{7}{|l|}{ Adj $R^{2}=0.262$} \\
\hline Polyunsaturated fat (g) & 0.015 & 0.007 & 0.225 & 2.247 & $0.002-0.028$ & 0.03 \\
\hline Maternal BMI $\left(\mathrm{kg} / \mathrm{m}^{2}\right)$ & 0.059 & 0.014 & 0.439 & 4.255 & $0.031-0.086$ & $<0.001$ \\
\hline Infant gender & 0.151 & 0.118 & 0.128 & 1.287 & $-0.083-0.386$ & 0.20 \\
\hline Gestational age at birth & 0.007 & 0.039 & 0.019 & 0.185 & $-0.083-0.386$ & 0.85 \\
\hline
\end{tabular}

Dependent variable: FMl; g, grams; mg, milligram.

Table 4 outlines three models of multivariable linear regression analysis of WFFQ nutrient intakes and neonatal FMI. On multivariable regression, only the relationship between polyunsaturated fat and neonatal FMI persisted in all three models (Model 1 beta $=0.036,95 \%$ CI $=$ 0.002-0.076, $P=0.04$; Model 2 beta $=0.035,95 \% \mathrm{CI}=$ $0.000-0.069, P=0.047$; Model 3 beta $=0.015,95 \% \mathrm{CI}=$ $0.002-0.028, P=0.03)$.

\section{Discussion}

\section{Main finding of this study}

This prospective observational study found that maternal dietary intakes of polyunsaturated fat in early pregnancy are positively associated with neonatal FMI on multivariable analysis. There was no relationship between maternal macroor micro-nutrient intakes in early pregnancy and birthweight $(P>0.05)$. Given the emerging data suggesting associations between maternal dietary intakes and neonatal adiposity, further longitudinal studies are needed to explore this association and its long-term implications for the neonate.
Strengths of this study include that gestational age was confirmed by ultrasound scan, rather than estimated based on the last menstrual period. ${ }^{45}$ Second, ADP was used to measure neonatal body composition. This is a validated, direct measurement of neonatal birthweight and volume, which is used to calculate neonatal fat mass, fat free mass and percentage body fat. ${ }^{40,41,46}$ Further strengths are that maternal height and weight were measured rather than selfreported. This ensured accurate calculation and classification of maternal BMI. Individual PALs were also collected for participants, facilitating more accurate identification and removal of respondents who had misreported their dietary intakes. ${ }^{33}$

\section{What is already known about this topic}

Appropriate maternal nutritional intakes in pregnancy are important determinants of the long-term health status of the neonate. Inadequate intakes of key micro-nutrients at critical periods of gestation can have lasting deleterious effects on the developing foetus. ${ }^{4}$ For example, deficiencies in maternal 
iron status have been linked with lower birthweight ${ }^{16}$ and poorer cognitive development ${ }^{47,48}$ while low folate status is a critical risk factor for neural tube defect (NTD) births. ${ }^{5}$ Research has shown deficiencies of nutrients at sensitive periods of gestation may compromise the long-term health of the foetus by subverting normal tissue growth and organogenesis in the cardiovascular, respiratory, gastrointestinal, musculo-skeletal, neurological, immune and endocrine systems. ${ }^{49-51}$ Conversely, excess nutrient intakes can also influence foetal growth. Excessive intakes of fat, saturated fat ${ }^{52}$ and refined sugar ${ }^{53}$ during gestation have been linked to adverse maternal metabolic consequences, which can adversely affect foetal growth.

Data describing the influence of maternal dietary intakes on birthweight and neonatal body composition are continuing to emerge. A secondary analysis of the Healthy Start study $^{54}$ examined the relationship between maternal dietary quality during pregnancy and neonatal adiposity amongst 1079 mother-infant dyads. This study found that poor dietary scores $(\leq 57)$ as determined by using the Healthy Eating Index 2010 dietary quality scoring system, were associated with higher neonatal fat mass and percentage body fat $(P<$ 0.05). However, this study differed to our study design in terms of its dietary assessment methodology. The study population also excluded those with prior diabetes mellitus and included pregnant women up to 24 weeks gestation.

A further study investigated the associations between maternal macronutrient intake, carbohydrate quality (GI Index) and neonatal body composition, in women at risk of GDM. $^{14}$ This study identified trimester specific effects of specific dietary intakes on neonatal body composition, and suggested that over consumption of carbohydrates and high glycaemic (GI) index foods at sensitive stages of gestation may compromise fat free mass accretion in the foetus which persists at birth. Additionally, this study highlighted that high fat and saturated fat intakes in mid-pregnancy were positively associated with neonatal fat free mass index, while in late pregnancy, high intakes of these macronutrients were positively associated with neonatal FMI. ${ }^{14}$

Further results from a secondary analysis of the ROLO study (Randomized cOntrol trial of LOw glycaemic index diet versus no dietary intervention to prevent recurrence of foetal macrosomia) found that maternal saturated fat intakes were positively associated with neonatal adiposity. ${ }^{55}$ This study however, only recruited women who were secundigravida with a previous macrosomic baby $(>4.0 \mathrm{~kg})$.

To date, the findings in relation to the relationship between omega fatty acids, fish oils and birth outcomes is mixed. In a large observational study, low-maternal plasma levels of certain omega- 3 and omega- 6 fatty acids, and high concentrations of other omega- 6 fatty acids in early pregnancy, were associated with decreased foetal growth, decrease in birthweight, and increased risk of small for gestational age (SGA) infants. Additionally, neonates born to the women in the study cohort with the most adverse fatty acid profile, were on average $125 \mathrm{~g}$ lighter and twice as likely to be SGA. ${ }^{56}$

A systematic review concluded that omega-3 LC PUFA supplementation during pregnancy resulted in a modest increase in birthweight. ${ }^{57}$ Disproportionate consumption of fish in high quantities may result in a negative relationship with birthweight. While research suggests a positive association with omega-3 supplementation and birthweight, the appropriate dose requires verification. ${ }^{58-60}$

A US study found that higher n23 PUFA concentrations in the maternal diet and in umbilical cord plasma phospholipids, were associated with lower adiposity in children at age 3 years as measured by the sum of skinfold thicknesses, likelihood of obesity, and the concentration of leptin (a biomarker directly correlated with adiposity). Higher maternal fish intake in pregnancy, a primary source of n23 PUFA, was also associated with lower child adiposity. ${ }^{61}$

\section{What this study adds}

While there is extensive literature on the impact of isolated nutrients and birthweight, and emerging data with regard to adiposity composition measurements, to our knowledge, this is the first study to investigate the association between a wide range of macro-and micro-nutrients in early pregnancy with birthweight and neonatal adiposity using a direct measurement, in the same study cohort.

Pregnancy offers a unique opportunity to enhance maternal lifestyle behaviours which could yield more favourable neonatal health outcomes at birth and across the life course. $^{1,23}$ Our study findings suggest that dietary interventions in early pregnancy which target maternal dietary fat intake could influence neonatal adiposity at birth. Further longitudinal studies need to explore this association and evaluate the lifelong implications.

While the associations between neonatal body composition and long-term health outcomes remain to be fully elucidated, there is suggestive evidence that higher neonatal abdominal circumference (as a proxy of visceral adiposity) is associated with less favourable metabolic status in early childhood. $^{23}$ This suggests that maternal food and nutrient intakes which influence differences in neonatal body composition may impact long-term health outcomes in offspring. 


\section{Limitations}

A limitation of this study is the small sample population for neonatal adiposity data. Of the women recruited to the study, PEA POD $^{\circledR}$ measurements with corresponding maternal FFQ data on plausible reporters were available on 80 neonates; a sample size similar to that of other studies measuring neonatal body composition by air-displacement plethysmography. ${ }^{14,40}$ This sample size however, may be insufficient to power inferential statistical analysis.

A further potential limitation of the study is the convenience recruitment method. This methodology can result in the recruitment of participants who differ from the wider population. However, the characteristics of our study population were similar to those of the broader hospital population ${ }^{28}$ and to the national normative range for neonatal anthropometric measurements ${ }^{42}$ suggesting that they are generally representative of their peers. Also, consecutive recruitment of pregnant women in a busy clinical service is not feasible.

\section{Acknowledgements}

We would like to acknowledge and express thanks to all participants who took part in this study.

\section{References}

1. Lillycrop KA, Burdge GC. Epigenetic mechanisms linking early nutrition to long term health. Best Pract Res Clin Endocrinol Metab 2012;26:667-76.

2 Catalano PM, McIntyre HD, Cruickshank JK et al. The hyperglycemia and adverse pregnancy outcome study: associations of GDM and obesity with pregnancy outcomes. Diabetes Care 2012;35:780-6.

3 Daraki V, Georgiou V, Papavasiliou S et al. Metabolic profile in early pregnancy is associated with offspring adiposity at 4 years of age: the Rhea pregnancy cohort Crete, Greece. PLoS One 2015;10: e0126327.

4 Adamo KB, Ferraro ZM, Brett KE. Pregnancy is a critical period for prevention of obesity and cardiometabolic risk. Can J Diabetes 2012;36:133-41.

5 Cawley S, Mullaney L, McKeating A et al. An analysis of folic acid supplementation in women presenting for antenatal care. I Public Health (Oxf) 2015;38:122-9.

6 Barker DJ. Early growth and cardiovascular disease. Arch Dis Child 1999;80:305-7.

7 Law CM, Shiell AW. Is blood pressure inversely related to birth weight? The strength of evidence from a systematic review of the literature. J Hypertens 1996;14:935-42.

8 Langley-Evans SC. Nutrition and early life and the programming of adult disease: a review. J Hum Nutr Diet 2015;28:1-4.

9 Barker DJ. In utero programming of chronic disease. Clin Sci (Lond) 1998;95:115-28.
$10 \mathrm{Gu}$ S, An X, Fang L et al. Risk factors and long-term health consequences of macrosomia: a prospective study in Jiangsu Province, China. J Biomed Res 2012;26:235-40.

11 Savona-Ventura C, Chircop M. Birth weight influence on the subsequent development of gestational diabetes mellitus. Acta Diabetol 2003;40:101-4.

12 Ferreira AP, da Silva JR Jr, Figueiroa JN et al. Abdominal subcutaneous and visceral fat thickness in newborns: correlation with anthropometric and metabolic profile. J Perinatol 2014;34:932-5.

13 Karamali NS, Ariëns GA, Kanhai HH et al. Thin-fat insulin-resistant phenotype also present in South Asian neonates born in the Netherlands. J Dev Orig Health Dis 2015;6:47-52.

14 Kizirian NV, Markovic TP, Muirhead R et al. Macronutrient balance and dietary glycemic index in pregnancy predict neonatal body composition. Nutrients 2016;8:270.

15 Haggarty P. Fatty acid supply to the human fetus. Annu Rev Nutr 2010;30:237-55.

16 Haider BA, Olofin I, Wang M et al. Anaemia, prenatal iron use, and risk of adverse pregnancy outcomes: systematic review and metaanalysis. BMJ 2013;346:f3443.

17 Harvey NC, Holroyd C, Ntani G et al. Vitamin D supplementation in pregnancy: a systematic review. Health Technol Assess 2014;18: 1-190.

18 Hewison M, Adams JS. Vitamin D insufficiency and skeletal development in utero. J Bone Miner Res 2010;25:11-3.

19 Miliku K, Vinkhuyzen A, Blanken LM et al. Maternal vitamin D concentrations during pregnancy, fetal growth patterns, and risks of adverse birth outcomes. Am J Clin Nutr 2016;103:1514-22.

20 Mojibian M, Soheilykhah S, Fallah Zadeh MA et al. The effects of vitamin D supplementation on maternal and neonatal outcome: A randomized clinical trial. Iran J Reprod Med 2015;13:687-96.

21 Blumfield ML, Hure AJ, MacDonald-Wicks LK et al. Dietary balance during pregnancy is associated with fetal adiposity and fat distribution. Am J Clin Nutr 2012;96:1032-41.

22 Gresham E, Byles JE, Bisquera A et al. Effects of dietary interventions on neonatal and infant outcomes: a systematic review and meta-analysis. Am J Clin Nutr 2014;100:1298-321.

23 Tanvig M. Offspring body size and metabolic profile-effects of lifestyle intervention in obese pregnant women. Dan Med J 2014;61: B4893.

24 Chen L, Tint M, Fortier MV et al. Maternal macronutrient intake during pregnancy is associated with neonatal abdominal adiposity: the Growing Up in Singapore Towards healthy Outcomes (GUSTO) study. J Nutr 2016;146:1571-9.

25 De Cunto A, Paviotti G, Ronfani L et al. Can body mass index accurately predict adiposity in newborns? Arch Dis Child Fetal Neonatal Ed 2014;99:F238-9.

26 Grieger JA, Clifton VL. A review of the impact of dietary intakes in human pregnancy on infant birthweight. Nutrients 2014;7:153-78.

27 Mullaney L, O'Higgins AC, Cawley S et al. Breast-feeding and postpartum maternal weight trajectories. Public Health Nutr 2016;19: 1397-404.

28 Coombe Women and Infants University. Hospital annual clinical report. HSE Print and Design, 2014. 
29 Kaaks R, Slimani N, Riboli E. Pilot phase studies on the accuracy of dietary intake measurements in the EPIC project: overall evaluation of results. European prospective investigation into cancer and nutrition. Int J Epidemiol 1997;26:S26-36.

30 Harrington $\mathrm{J}$. Validation of a food frequency questionnaire as a tool for assessing nutrient intake. MA Thesis. Health Promotion. Galway: National University of Ireland, Galway, 1997.

31 Morgan K, McGee H, Watson D et al. SLÁN 2007: survey of lifestyle, attitudes and nutrition in Ireland. Main Report, Department of Health and Children. Dublin: The Stationery Office, 2008.

32 McGowan CA, Curran S, McAuliffe FM. Relative validity of a food frequency questionnaire to assess nutrient intake in pregnant women. J Hum Nutr Diet 2014;27:167-74.

33 Mullaney L, O’Higgins AC, Cawley S et al. An estimation of periconceptional under-reporting of dietary energy intake. J Public Health (Oxf) 2014;37:728-36.

34 Food Standards Agency. Food portion sizes. 3rd edn. London: TSO, 2006.

35 Food and Agricultural Organisation/World Health Organisation/ United Nations University. Human energy requirements. Report of a Joint FAO/WHO/UNU Expert Consultation. Rome: Food and Agricultural Organisation, 2001.

36 Henry CJ. Basal metabolic rate studies in humans: measurement and development of new equations. Public Health Nutr 2005;8:1133-52.

37 Black AE. Critical evaluation of energy intake using the Goldberg cut-off for energy intake: basal metabolic rate. A practical guide to its calculation, use and limitations. Int $J$ Obes Relat Metab Disord 2000;24:1119-30.

38 Goldberg GR, Black AE, Jebb SA et al. Critical evaluation of energy intake data using fundamental principles of energy physiology: 1. Derivation of cut-off limits to identify under-recording. Eur J Clin Nutr 1991;45:569-81.

39 Black AE, Coward WA, Cole TJ et al. Human energy expenditure in affluent societies: an analysis of 574 doubly-labelled water measurements. Eur J Clin Nutr 1996;50:72-92.

40 Deierlein AL, Thornton J, Hull $\mathrm{H}$ et al. An anthropometric model to estimate neonatal fat mass using air displacement plethysmography. Nutr Metab (Lond) 2012;9:21.

41 Ma G, Yao M, Liu Y et al. Validation of a new pediatric airdisplacement plethysmograph for assessing body composition in infants. Am J Clin Nutr 2004;79:653-60.

42 Hawkes CP, Hourihane JO, Kenny LC et al. Gender-and gestational age-specific body fat percentage at birth. Pediatrics 2011;128:e645-51.

43 Wells JC. A critique of the expression of paediatric body composition data. Arch Dis Child 2001;85:67-72.

44 Wells JC. Toward body composition reference data for infants, children, and adolescents. Adv Nutr 2014;5:320S-9.

45 Lynch CD, Zhang J. The research implications of the selection of a gestational age estimation method. Paediatr Perinat Epidemiol 2007;21: 86-96.
46 Ellis KJ, Yao M, Shypailo RJ et al. Body-composition assessment in infancy: air-displacement plethysmography compared with a reference 4-compartment model. Am J Clin Nutr 2007;85:90-5.

47 Tran TD, Biggs BA, Tran T et al. Impact on infants' cognitive development of antenatal exposure to iron deficiency disorder and common mental disorders. PLoS One 2013;8:e74876.

48 Radlowski EC, Johnson RW. Perinatal iron deficiency and neurocognitive development. Front Hum Neurosci 2013;7:585.

49 Christian P, Stewart CP. Maternal micronutrient deficiency, fetal development, and the risk of chronic disease. I Nutr 2010;140: 437-45.

50 Uriu-Adams JY, Keen CL. Zinc and reproduction: effects of zinc deficiency on prenatal and early postnatal development. Birth Defects Res B Dev Reprod Toxicol 2010;89:313-25.

51 Taylor PN, Okosieme OE, Dayan CM et al. Therapy of endocrine disease: impact of iodine supplementation in mild-to-moderate iodine deficiency: systematic review and meta-analysis. Eur J Endocrinol 2014;170:R1-5.

52 Bowers K, Tobias DK, Yeung E et al. A prospective study of prepregnancy dietary fat intake and risk of gestational diabetes. $A m J$ Clin Nutr 2012;95:446-53.

53 Regnault TR, Gentili S, Sarr O et al. Fructose, pregnancy and later life impacts. Clin Exp Pharmacol Physiol 2013;40:824-37.

54 Shapiro AL, Kaar JL, Crume TL et al. Maternal diet quality in pregnancy and neonatal adiposity: the Healthy Start Study. Int J Obes (Lond) 2016;40:1056-62.

55 Horan MK, McGowan CA, Gibney ER et al. Maternal low glycaemic index diet, fat intake and postprandial glucose influences neonatal adiposity-secondary analysis from the ROLO study. Nutr J 2014;13:78.

56 van Eijsden M, Hornstra G, van der Wal MF et al. Maternal n-3, n6 , and trans fatty acid profile early in pregnancy and term birth weight: a prospective cohort study. Am J Clin Nutr 2008;87:887-95.

57 Imhoff-Kunsch B, Briggs V, Goldenberg T et al. Effect of n-3 longchain polyunsaturated fatty acid intake during pregnancy on maternal, infant, and child health outcomes: a systematic review. Paediatr Perinat Epidemiol 2012;26:91-107.

58 Grandjean P, Bjerve KS, Weihe $\mathrm{P}$ et al. Birthweight in a fishing community: significance of essential fatty acids and marine food contaminants. Int J Epidemiol 2001;30:1272-8.

59 Oken E, Kleinman KP, Olsen SF et al. Associations of seafood and elongated n-3 fatty acid intake with fetal growth and length of gestation: results from a US pregnancy cohort. Am J Epidemiol 2004;160: $774-83$.

$60 \mathrm{Ma} \mathrm{N}$, Hardy DB. The fetal origins of the metabolic syndrome: Can we intervene? J Pregnancy 2012;2012:482690.

61 Donahue SM, Rifas-Shiman SL, Gold DR et al. Prenatal fatty acid status and childhood adiposity at age 3y: results from a US pregnancy cohort. Am J Clin Nutr 2011;93:780-8. 